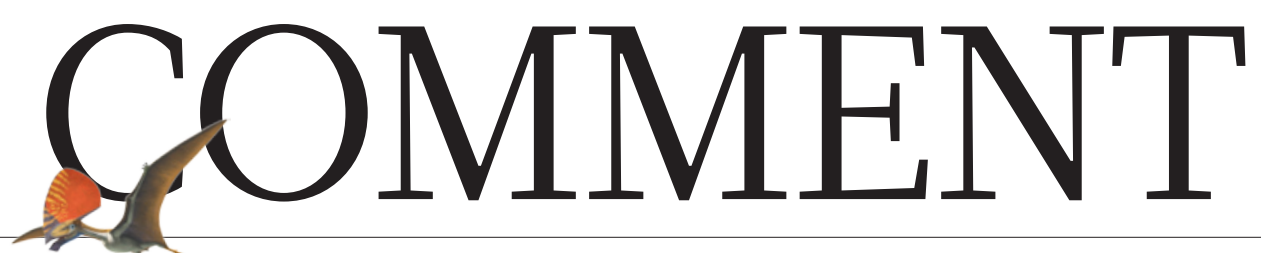

CULTURE This year's hot tickets, from opera to theatre, museums to movies p.22
PHYSICS A compelling personal manifesto for the multiverse, on four levels p.24
EDUCATION Massive open online course for dementia carers reaches new learners $\mathbf{p . 2 6}$
OBITUARY Frederick Sanger, winner of two Nobel prizes, remembered $\mathbf{p . 2 7}$

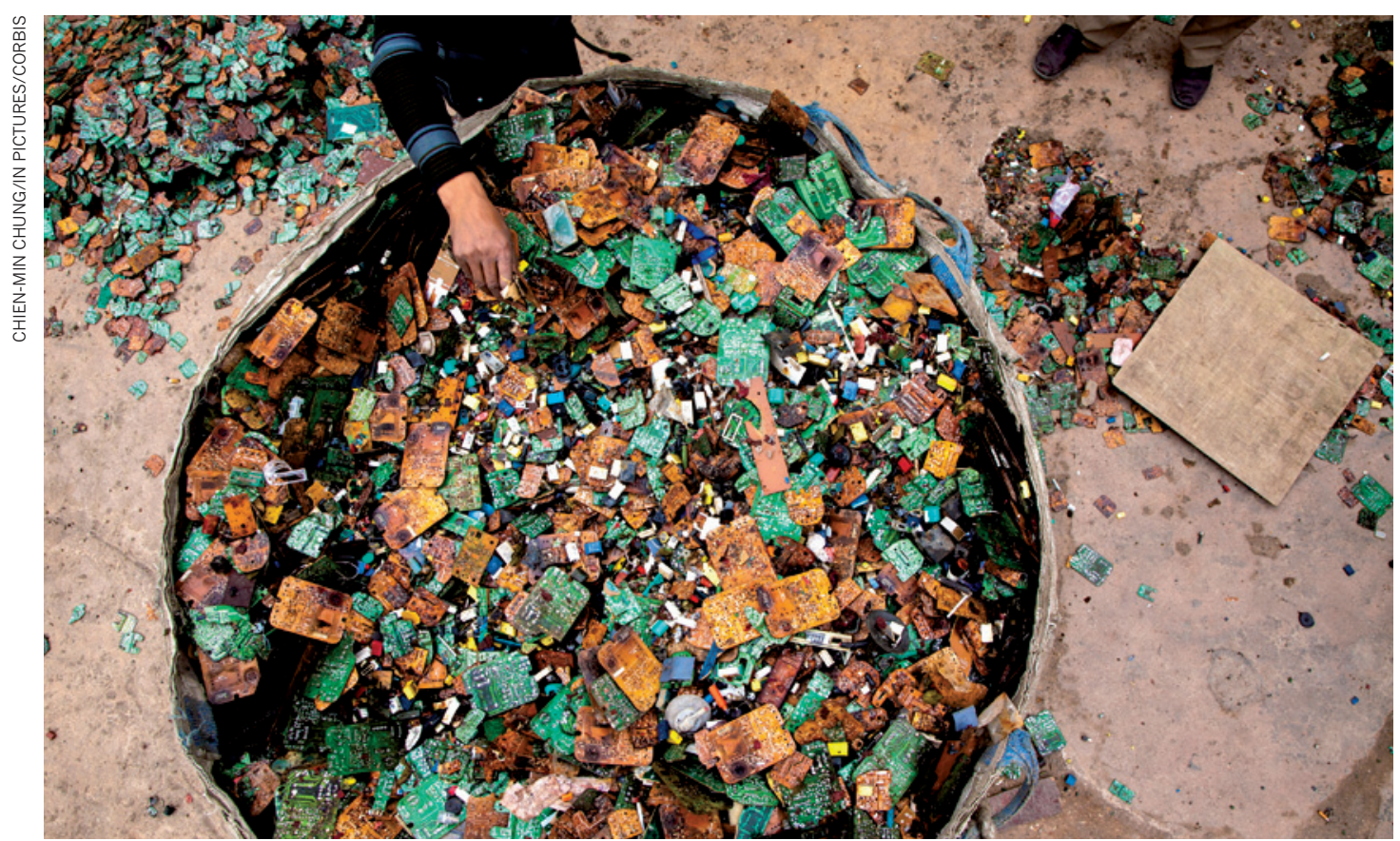

A worker sorts through stripped computer boards in Guiyu, China.

\title{
Track flows to manage technology-metal supply
}

Recycling cannot meet the demand for rare metals used in digital and green technologies, says Andrew Bloodworth. A more holistic approach is needed.

$\mathrm{D}$ emand for metals is soaring as the global population booms and millions of people in emerging economies aspire to a Western lifestyle. The variety of metals we use has also expanded as technology has advanced. As a result, historic fears regarding metal scarcity and resource depletion have returned in the past ten years.

Concerns focus on the future supply of metals such as indium, lithium, rare-earth elements, tellurium and germanium, all of which are crucial to delivering new digital and low-carbon energy technologies, including photovoltaics and electric cars.

In 2009, the issue came to global prominence when China reduced its exports of rare-earth elements, as the government sought to maintain supply to its rapidly expanding domestic manufacturing sector.

Geopolitical and socio-economic risks such as territorial disputes in Asia or labour relations in southern Africa - can interrupt supply because technology metals are produced in very few locations. Commercial barriers compound the issue. Investment in these materials can be risky because they are difficult to extract and the markets are small, complex and volatile compared with those for iron, copper and aluminium.

To secure supplies of metals for future technology, the scientific, industrial and policy communities must work together. The numerous assessments that governments have commissioned fall short. They identify key issues, but generate lots of sterile argument as to whether a particular metal is 'critical'. The solutions they point to are generic and of little practical use.

Prominent among these broad-brush responses has been the implication that the security of technology-metal supply in mainland Europe and the United Kingdom can be achieved mostly through recycling. Although recycling is important for managing stocks of common industrial metals, its application to technology metals is more complex. Some materials are impractical or impossible to retrieve after use. 
> More primary sources will be needed to meet rising demand and replace lost technology metals. To find new resources, the geological processes that concentrate these metals need to be better understood. And to increase efficiency and avoid unintended environmental impacts, the flows of individual metals need to be mapped from the ground to the end of their use.

\section{RARE RESOURCES}

Demand for technology metals has exploded in the past 40 years, with $80 \%$ of the cumulative global production of gallium, rareearth elements, platinum-group metals and indium taking place since 1980 (ref. 1). Growth is expected to continue for the foreseeable future ${ }^{2}$.

Most technology metals are mined in only a few places. In 2011, for example, $72 \%$ of global cobalt came from the Democratic Republic of the Congo ${ }^{3}$ and $57 \%$ of indium originated from China (see go.nature.com/crtooz and 'Metal producers'). Such metals are produced in low quantities. In 2011, just 72,900 tonnes of tungsten was extracted globally, compared with 45.2 million tonnes of aluminium and 1.5 billion tonnes of crude steel $^{3}$.

Some studies have concluded that scarcity and depletion of technology metals are unavoidable as rising consumption will exceed current reserves ${ }^{4}$. These apocalyptic forecasts fail to take into account that geological reserves are dynamic, expanding as metal prices rise and extraction of lower-grade ores becomes economical and tractable, and contracting as prices fall. A combination of price pressures and technical advances has kept global reserves of most metals steady or growing over the past 50 years ${ }^{5}$.

Because technology metals were of limited economic interest until recently, there has been little imperative to look for them. Consequently, not much is known about their distribution in Earth or the natural processes that concentrate them.

As knowledge improves, we will be able to reappraise old mining areas and explore new frontiers. Former mines in southwest England might hold promise for tungsten, for example, and a significant deposit of heavy rare-earth elements was identified in 2009 at Norra Kärr in Sweden. However, overcoming public objections to new mines can be a major challenge, especially in the developed world, where populations are often reluctant to accept the resource consequences of conspicuous consumption.

\section{RECYCLING IS NOT ENOUGH}

Secondary metals, recycled from defunct products, provide valuable supplementary resources. But secondary stock will never meet growing demand. And recycling has technical limits.

From mobile phones to motor vehicles,

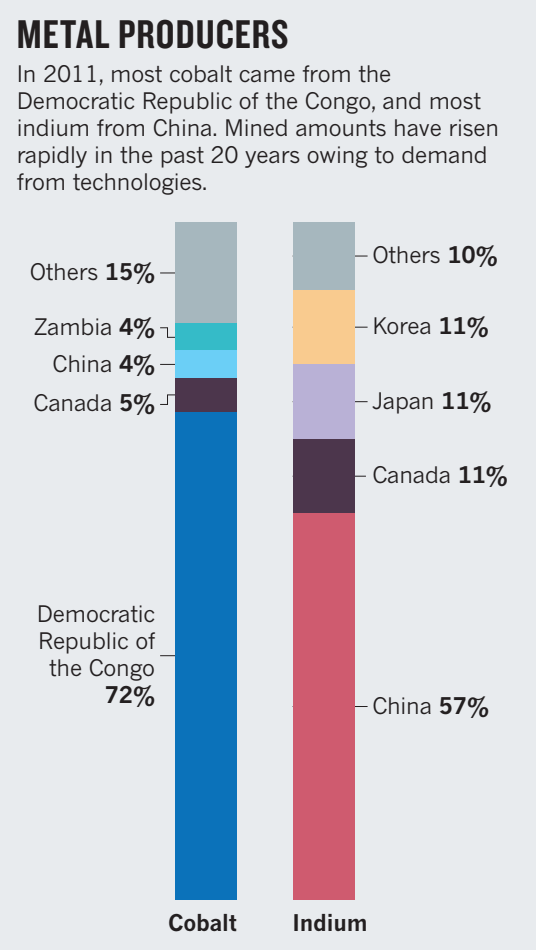

technology metals are used in myriad applications. Up to 60 different elements go into the manufacture of microprocessors and circuit boards ${ }^{6}$, usually in tiny quantities and often in combinations that are not found in nature.

Whether a metal can be recovered once a device is defunct depends on the element's value, concentration and accessibility when it is combined with other materials ${ }^{7}$. Precious metals - platinum-group metals and gold are the main target in the processing of used circuit boards. Lower-value copper, antimony and indium can be recovered at the same time. But metals such as tantalum, gallium, germanium and rare-earth elements are oxidized and effectively lost in the smelter slag ${ }^{1}$.

Recycling technology metals is most economically attractive when they are highly concentrated, for example in manufacturing scrap. Around $70 \%$ of the indium used in producing flat-screen displays, for example, finds its way into scrap, which is then recycled ${ }^{8}$.

To fix bottlenecks and inefficiencies requires measuring technology-metal stocks and understanding how they flow through the whole supply chain - from mining to concentration, extractive and process metallurgy, manufacturing, use, reuse, recycling, dispersal and disposal ${ }^{9}$. For instance, improving recovery technology at tungsten mines would increase the amount of the metal in the ore that ends up reaching the smelter (just $75 \%$ for tungsten, in contrast to $90 \%$ for gold).

In theory, more than $90 \%$ of platinumgroup metals used in autocatalysts can be recovered. In practice, only $50-60 \%$ is retrieved from European scrap cars because many vehicles are exported second-hand to places that lack recycling facilities. Analysis of metal flows could show whether a scheme to retrieve lost catalytic converters would be more effective than another type of scheme, such as a 2011 proposal by a UK waste-management company to recover these metals from road sweepings. Autocatalysts contain about $0.2 \%$ platinum-group metals; sweepings contain less than 1 part per million ${ }^{10}$.

Addressing technological barriers to resource efficiency in this way is a focus of initiatives, such as the European Innovation Partnership on Raw Materials - a network of European countries aimed at increasing the availability of raw materials across the region.

However, mapping the life cycle of critical metals is challenging. The volumes are low; extraction, processing and recycling are handled by just a few organizations; and commercial confidentiality can make data and contacts hard to find.

\section{ONE SYSTEM}

In the past five years, concerns over securing supplies of technology metals have evolved from near-panic over physical depletion and Chinese geopolitical muscle-flexing, to a dangerous assumption by some policymakers that recycling is the panacea. A more holistic approach is needed.

Primary and secondary sources must be considered as part of one system that needs to be wholly understood. Basic statistical data are crucial. Better dialogue between producers, processors, consumers and recyclers will be needed. Policy-makers must assess how technology metals are used and combined, and the impact this has on the economic and environmental viability of recycling them.

The benefits of securing supplies of technology metals are clear. Improving the efficiency and reducing the environmental footprint of extraction and processing of these metals from primary sources is a major opportunity for industry and researchers.

Andrew Bloodworth is science director for minerals and waste at the British Geological Survey, Nottingham, UK.

e-mail:ajbl@bgs.ac.uk

1. Hagelüken, C., Drielsmann, R. \& Ven den Broeck, K. in Precious Materials Handbook (eds Sehrt, U. \& Grehl, M.) Ch. 1 (Hanua-Wolfgang, 2012).

2. Graedel, T. E. \& Erdmann, L. Mat. Res. Soc. Bull. 87, 325-331 (2012).

3. British Geological Survey World Mineral Production 2007-2011 (BGS, 2013)

4. Ragnarsdóttir, K. V. Nature Geosci. 1, 720-721 (2008).

5. Crowson, P. C. F. Mineral Econ. 24, 1-6 (2011).

6. Gunn, A. G. in Proc. 12th Bienn. Soc. Geol. Appl. Miner. Depos. Meet. (SGA, 2013).

7. Reck, B. K. \& Graedel, T. E. Science 337, 690-695 (2012).

8. Jackson, B. \& Mikolajczak, C. Availability of Indium and Gallium (Indium Corporation, 2012).

9. Allwood, J. M. \& Cullen, J. M. Sustainable Materials (UIT Cambridge, 2012).

10.Jackson, M. T., Sampson, J. \& Pritchard, H. M. Sci. Total Environ. 385, 1-3 (2007). 